\title{
The effect of acute exercise on glycogen synthesis rate in obese subjects studied by ${ }^{13} \mathrm{C}$ MRS
}

\author{
Marinette van der Graaf • Jacco H. de Haan • \\ Paul Smits · Alexandra H. Mulder • \\ Arend Heerschap • Cees J. Tack
}

Accepted: 7 September 2010/Published online: 24 September 2010

(C) The Author(s) 2010. This article is published with open access at Springerlink.com

\begin{abstract}
In obesity, insulin-stimulated glucose uptake in skeletal muscle is decreased. We investigated whether the stimulatory effect of acute exercise on glucose uptake and subsequent glycogen synthesis was normal. The study was performed on 18 healthy volunteers, 9 obese $\left(\mathrm{BMI}=32.6 \pm 1.2 \mathrm{~kg} / \mathrm{m}^{2}\right.$, mean $\left.\pm \mathrm{SEM}\right)$ and 9 lean $\left(B M I=22.0 \pm 0.9 \mathrm{~kg} / \mathrm{m}^{2}\right.$ ), matched for age and gender. All participants underwent a euglycemic hyperinsulinemic clamp, showing reduced glucose uptake in the obese group $(P=0.01)$, during which they performed a short intense local exercise (single-legged toe lifting). Dynamic glucose incorporation into glycogen in the gastrocnemius muscle before and after exercise was assessed by ${ }^{13} \mathrm{C}$ magnetic resonance spectroscopy combined with infusion of $\left[1-{ }^{13} \mathrm{C}\right]$ glucose. Blood flow was measured to investigate its potential contribution to glucose uptake. Before exercise, glycogen synthesis rate tended to be lower in obese subjects compared with lean (78 \pm 14 vs. $132 \pm 24 \mu \mathrm{mol} / \mathrm{kg}$ muscle $/ \mathrm{min} ; P=0.07$ ). Exercise induced highly significant rises in glycogen synthesis rates in both groups, but the increase in obese
\end{abstract}

Communicated by Susan Ward.

M. van der Graaf $(\bowtie) \cdot$ J. H. de Haan · A. Heerschap Department of Radiology, 667, Radboud University Nijmegen Medical Centre, P.O. box 9101, 6500 HB Nijmegen,

The Netherlands

e-mail: M.vanderGraaf@rad.umcn.nl

P. Smits

Department of Pharmacology-Toxicology, Radboud University Nijmegen Medical Centre, Nijmegen, The Netherlands

A. H. Mulder · C. J. Tack

Department of General Internal Medicine, Radboud University Nijmegen Medical Centre, Nijmegen, The Netherlands subjects was reduced compared with lean $(112 \pm 15$ vs. $186 \pm 27 \mu \mathrm{mol} / \mathrm{kg}$ muscle $/ \mathrm{min} ; P=0.03$ ), although the relative increase was similar $(184 \pm 35$ vs. $202 \pm 51 \%$; $P=0.78)$. After exercise, blood flow increased equally in both groups, without a temporal relationship with the rate of glycogen synthesis. In conclusion, this study shows a stimulatory effect of a short bout of acute exercise on insulin-induced glycogen synthesis rate that is reduced in absolute values but similar in percentages in obese subjects. These results suggest a shared pathway between insulin- and exercise-induced glucose uptake and subsequent glycogen synthesis.

Keywords Exercise - Glycogen synthesis rate - Insulin resistance $\cdot{ }^{13} \mathrm{C}$ magnetic resonance spectroscopy . Obesity $\cdot$ Muscle

\section{Introduction}

Insulin resistance is characterized by a decreased insulinstimulated glucose uptake in skeletal muscle (Shulman et al. 1990). In vivo experiments have demonstrated that not only insulin, but also muscle contraction is able to stimulate glucose uptake (Richter et al. 1989; Cushman et al. 1998; Ivy and Kuo 1998; Kennedy et al. 1999; Thorell et al. 1999). This stimulation has been suggested to occur via a route independent of insulin signaling (Lund et al. 1995). This raises the possibility that subjects, who are resistant to the effects of insulin on glucose uptake, may respond normal to the effects of exercise on glucose uptake. Indeed, Martin et al. (1995) reported a similar increase in leg glucose uptake at the end of a 40-min exercise period in type 2 diabetic patients compared with controls, which is in accordance 
with earlier reports (Minuk et al. 1981; Shulman et al. 1990). Also Price et al. (1996) showed normal rates of glycogen synthesis during an initial insulin-independent phase directly after exercise in insulin-resistant offspring of parents with type 2 diabetes, followed by diminished rates during a later insulin-dependent phase. Nevertheless, other studies suggest the presence of an interaction between insulin-stimulated and contraction-induced glucose uptake in muscle with a reduced stimulating effect of exercise in insulin-resistant subjects (Perseghin et al. 1996; Peltoniemi et al. 2001; Hällsten et al. 2003; Slimani et al. 2006). Part of these differences may be caused by a difference in intensity of the exercise, because only very rigorous depletion of glycogen as a result of intense exercise may result in an initial insulinindependent glycogen resynthesis followed by an insulindependent phase (Price et al. 1994).

Most studies have focused on the effect of exercise in itself, often during or at the end of an extensive period of intensive exercise or after a training program. However, it should be noted that even after a single bout of exercise, the action of insulin may improve for as long as 2 days (Wojtaszewski et al. 2003). In a preliminary study, we investigated the effects of a short bout of acute exercise on human muscle glucose metabolism in healthy volunteers using ${ }^{13} \mathrm{C}$ - and ${ }^{31} \mathrm{P}$-magnetic resonance (MR) spectroscopy. It was found that even a 2-min bout of local exercise resulted in a sustained increase in insulin-stimulated glycogen synthesis in skeletal muscle post-exercise (De Haan et al. 2002). Therefore, we hypothesize that these effects may be retained in insulin-resistant subjects, and that such a short bout of exercise may result in amplification of insulin-stimulated glucose uptake and glycogen synthesis. To test this hypothesis and to assess potential associations with insulin resistance, we studied obese subjects and compared them with age-matched healthy lean subjects using ${ }^{13} \mathrm{C}$ MR spectroscopy $\left({ }^{13} \mathrm{C}\right.$ MRS) of calf muscle before and immediately after a single bout of acute exercise. ${ }^{13} \mathrm{C}$ MRS in combination with infusion of ${ }^{13} \mathrm{C}$-enriched glucose (by hyperinsulinemic euglycemic clamp) enables continuous, non-invasive, dynamic measurement of glycogen synthesis in human skeletal muscle (Shulman et al. 1990; Van den Bergh et al. 2000; Serlie et al. 2005). Exercise was restricted to the calf muscle of a single leg to investigate local rather than systemic effects.

As exercise markedly increases blood flow thereby stimulating glucose delivery and uptake (Baron and Clark 1997; Rattigan et al. 2005), and because insulin-induced increase in blood flow is diminished in obese subjects (Tack et al. 1998), blood flow measurements were included in the study.

\section{Methods}

Subjects

We studied a total of 18 healthy volunteers of whom 9 had severe overweight or obesity $\left(\mathrm{BMI}=32.6 \pm 1.2 \mathrm{~kg} / \mathrm{m}^{2}\right.$, mean $\pm \mathrm{SEM})$ and 9 were lean $\left(\mathrm{BMI}=22.0 \pm 0.9 \mathrm{~kg} / \mathrm{m}^{2}\right)$. Subjects were divided into an obese and a lean control group, matched for age and gender. Subject characteristics are summarized in Table 1.

All volunteers underwent a clinical screening before being included. They were non-smoking, Caucasian and had no family history of diabetes, hypertension, or any other systemic disease. Except for oral contraceptives in female subjects, no medications were taken. None of the subjects was involved in any regular physical training program and the habitual physical activity of all subjects was comparable, as checked in an interview before inclusion in the study. The protocol was reviewed and approved by the Human Investigation Committee of the Radboud University Nijmegen Medical Centre and written consent was obtained from all subjects after explanation of the purpose, nature, and potential risks of the study.

\section{Experimental protocol}

For logistic reasons, MR examinations were performed in the early afternoon. After an overnight fast, subjects consumed a light breakfast (normal breakfast was replicated, with individually different food items, but only given 50\%) to prevent the stage of prolonged fasting (Hojlund et al. 2001) and fasted again for at least $4 \mathrm{~h}$ during the remainder of the morning until the MR examination. Then, a Teflon catheter was inserted into an antecubital vein in each arm, one for blood drawing and the other for glucose/insulin infusion. Baseline blood samples were taken for determination of plasma glucose and insulin concentrations and serum free fatty acid (FFA) levels. Thereafter, ${ }^{13} \mathrm{C}$ MRS measurements were started in combination with a euglycemic hyperinsulinemic clamp and infusion of ${ }^{13} \mathrm{C}$-enriched glucose to monitor glycogen synthesis in the calf muscle. After an hour of clamping, the ${ }^{13} \mathrm{C}$ MRS measurements were paused for a toe-lifting exercise outside the MR system as described below, during which the clamp was continued.

Hyperinsulinemic euglycemic clamp procedure

Insulin (Actrapid ${ }^{\circledR}$; Novo Nordisk, Denmark) infusion was started and continuously infused (360 pmol/ $\left.\left[\mathrm{m}^{2} \mathrm{~min}\right]\right)$ during the experimental protocol for $120 \mathrm{~min}$. Glucose $20 \%(\mathrm{w} / \mathrm{w})$ in solution was infused to maintain the plasma glucose concentration at $5 \mathrm{mmol} / \mathrm{L}$ for the ${ }^{13} \mathrm{C}$ MRS study. 
Table 1 Subject characteristics and clamp results

\begin{tabular}{lll}
\hline & $\begin{array}{l}\text { Lean } \\
(n=9)\end{array}$ & $\begin{array}{l}\text { Obese } \\
(n=9)\end{array}$ \\
\hline Gender & $7 \mathrm{~F}, 2 \mathrm{M}$ & $7 \mathrm{~F}, 2 \mathrm{M}$ \\
Age (years) & $36.3 \pm 6.4$ & $39.4 \pm 6.0$ \\
BMI $\left(\mathrm{kg} / \mathrm{m}^{2}\right)$ & $22.0 \pm 0.9$ & $32.6 \pm 1.2^{\mathrm{a}}$ \\
FFA, $t=0 \mathrm{~min}(\mathrm{mmol} / \mathrm{L})$ & $0.84 \pm 0.17$ & $0.77 \pm 0.07$ \\
FFA, clamp $(\mathrm{mmol} / \mathrm{L})$ & $0.08 \pm 0.02$ & $0.12 \pm 0.02$ \\
Insulin, $t=0 \mathrm{~min}(\mathrm{pmol} / \mathrm{L})$ & $47 \pm 15$ & $68 \pm 12$ \\
Insulin, $t=60 \mathrm{~min}(\mathrm{pmol} / \mathrm{L})$ & $484 \pm 28$ & $505 \pm 33$ \\
Insulin, $t=120 \mathrm{~min}(\mathrm{pmol} / \mathrm{L})$ & $447 \pm 30$ & $497 \pm 30$ \\
Glycogen, $t=0 \mathrm{~min}(\mathrm{mmol} / \mathrm{kg})$ & $68.2 \pm 5.3$ & $49.6 \pm 5.2^{\mathrm{b}}$ \\
Whole body glucose uptake & $38.5 \pm 4.8$ & $23.0 \pm 2.5^{\mathrm{c}}$ \\
$\quad(\mu \mathrm{mol} /[\mathrm{kg}$ min $])$ & & \\
\hline
\end{tabular}

${ }^{\mathrm{a}} P<0.0001,{ }^{\mathrm{b}} P=0.02,{ }^{\mathrm{c}} P=0.01$

The glucose solution was $30 \%$ enriched with $\left[1-{ }^{13} \mathrm{C}\right]$ glucose (Campro Scientific, Veenendaal, The Netherlands).

Blood samples were obtained at 7.5-min intervals for measurement of plasma glucose concentration and fractional plasma glucose ${ }^{13} \mathrm{C}$ enrichment or atom percentage excess (APE), and at 60-min intervals for plasma insulin. Plasma glucose concentration was measured in duplicate by the glucose oxidase method using a Beckman Glucose Analyzer (Glucose Analyzer II; Beckman, Fullerton, CA, USA). Blood plasma glucose enrichment levels were determined using high-resolution proton NMR at $11.7 \mathrm{~T}$ as previously described (Van den Bergh et al. 2000; Serlie et al. 2005).

\section{Exercise protocol}

After basal ${ }^{13} \mathrm{C}$ MRS measurement of insulin-stimulated synthesis of glycogen, subjects performed $1 \mathrm{~min}$ of singlelegged toe lifting (Price et al. 1994) with a rate of approximately one lift per second outside the MR system. Then, 1-min rest was allowed followed by another minute of toe lifting. Immediately after the exercise, the subjects were placed back in the MR system for further ${ }^{13} \mathrm{C}$ MRS measurements. The exercised leg was marked, to allow measurement at the same position. The workload of the exercise was calculated using the formula: work $=$ amount of lifts $\times$ height of the lift $\times$ weight of the subject $\times$ gravity constant.

\section{${ }^{13} \mathrm{C}$ MR spectroscopy}

During the MRS measurements, the subjects were lying supine inside the magnet of the whole body MR system (1.5 T Magnetom Vision, Siemens, Erlangen, Germany) with the calf muscle of the right leg positioned on top of a custom-made radiofrequency probe. For ${ }^{13} \mathrm{C}$ data acquisition, a surface coil of $13 \mathrm{~cm}$ in diameter was used. For ${ }^{1} \mathrm{H}$ acquisition, decoupling, and shimming, a circularly polarized coil with two loops of $15 \mathrm{~cm}$ in diameter was used (Adriany and Gruetter 1997). ${ }^{13} \mathrm{C}$ MR spectra were obtained in 15-min blocks consisting of 5,000 scans using an adiabatic pulse $(2,560 \mu$ s length $)$ and a repetition time of $180 \mathrm{~ms}$. During the first $60 \mathrm{~ms}$ of the acquisition period, continuous wave decoupling at $26 \mathrm{~W}$ at the proton frequency of the $\mathrm{C} 1{ }^{1} \mathrm{H}$ signal of glycogen was applied, staying well below specific absorption rate (SAR) safety limits. Quantification of the $\left[1-{ }^{13} \mathrm{C}\right]$ glycogen signal was performed by phantom replacement measurements using a phantom with $100 \mathrm{mmol} / \mathrm{L}$ glycogen, $50 \mathrm{mmol} / \mathrm{L}$ potassium chloride, $40 \mathrm{mmol} / \mathrm{L}$ creatine and $0.02 \%$ sodium azide in combination with coil sensitivity corrections (Slotboom et al. 1998; Ith et al. 2003; Van der Graaf et al. 2010). In this quantification procedure, corrections were applied for differences in the thickness of the subcutaneous lipid layer and in the amount of muscle present, which has been described previously in more detail (Van der Graaf et al. 2010).

\section{Blood flow measurements}

Insulin-induced increase in blood flow might be lower in obese and/or elderly people, so that the largest difference can be expected between young lean and elderly obese subjects. To test this, blood flow measurements were performed in a subset of the two groups consisting of five young lean and three elderly obese. On a separate day, these subjects returned and underwent the same protocol, only now without ${ }^{13} \mathrm{C}$ MRS measurements. Therefore, nonenriched glucose $20 \%$ solution could be used for infusion during the clamp. Blood flow was measured in both legs and in one forearm, using strain gauge plethysmography. Sixty minutes after the clamp had been started, the toelifting exercise protocol was performed and afterward blood flow measurements were continued as soon as possible.

\section{Data analysis}

Increments in muscle glycogen concentration were calculated from the change in $\left[1{ }^{13} \mathrm{C}\right]$ glycogen signal integral and the plasma $\left[1-{ }^{13} \mathrm{C}\right]$ glucose APE at the corresponding time point as previously described (Serlie et al. 2005). The rates of muscle glycogen synthesis before and after exercise were calculated from the slopes of the least-squares linear fit to the glycogen concentration curve up to $60 \mathrm{~min}$ (basal measurement) and for at least $52.5 \mathrm{~min}$ directly after the toe-lifting exercise, and expressed in $\mu \mathrm{mol} / \mathrm{kg}$ muscle/min. 
Plasma immunoreactive insulin concentrations were measured with a double antibody radioimmunoassay. Serum free fatty acids (FFA) levels were measured at baseline and before and after exercise and were determined with a commercially available ACS-ACOD method (Wako NEFA C test; Wako Chemicals, Neuss, Germany).

Statistical analysis was performed using the Graphpad software package (Graphpad Prism, San Diego, CA, USA). Glycogen synthesis rates before and after exercise were compared with paired two-tailed Student's $t$ tests and differences in rates and increments between groups were tested using unpaired two-tailed Student's $t$ tests. Correlations were calculated using the Pearson correlation coefficient. Data are expressed as mean \pm SEM unless otherwise indicated. A $P$ value $<0.05$ was considered significant.

\section{Results}

\section{Clamp experiments}

Plasma glucose levels were stable and remained at fasting levels in all experiments (Fig. 1). Insulin concentrations increased from $58 \pm 10$ at baseline to $496 \pm 21$ and $473 \pm 21$ (pmol/L) after 60 and $120 \mathrm{~min}$, respectively during the clamp. FFA levels dropped during the hyperinsulinemic euglycemic clamp and did not change after muscle contraction. Values of insulin and FFA per group are presented in Table 1. In this table, it is also shown that whole body glucose uptake is significantly higher in the lean subjects compared with the obese group $(P=0.01)$, which shows a reduced insulin sensitivity in the latter group.

During the clamp, the APE $\left[1-{ }^{13} \mathrm{C}\right]$ glucose increased due to labeled glucose infusion (Fig. 1) with the most rapid increase in APE in the lean group during the first $60 \mathrm{~min}$, followed by a slighter increase afterwards. The increase in APE was slower in the obese group, which is in agreement with a lower whole body glucose uptake as compared with the lean group, as mentioned above.

\section{Effects of insulin on glycogen synthesis}

Baseline glycogen content was lower in obese than in lean subjects $(P=0.02$, Table 1$)$. The effect of the exercise protocol on glycogen depletion was assessed in a separate measurement, which showed only a marginal glycogen depletion of less than $10 \%$ (data not shown).

Figure 2 shows typical time series of increasing ${ }^{13} \mathrm{C}$ MRS signals of $\left[1-{ }^{13} \mathrm{C}\right]$ glycogen and the $\alpha$ - and $\beta$-anomers of $\left[1-{ }^{13} \mathrm{C}\right]$ glucose during the euglycemic hyperinsulinemic clamp with $\left[1-{ }^{13} \mathrm{C}\right]$ glucose infusion for one subject of each
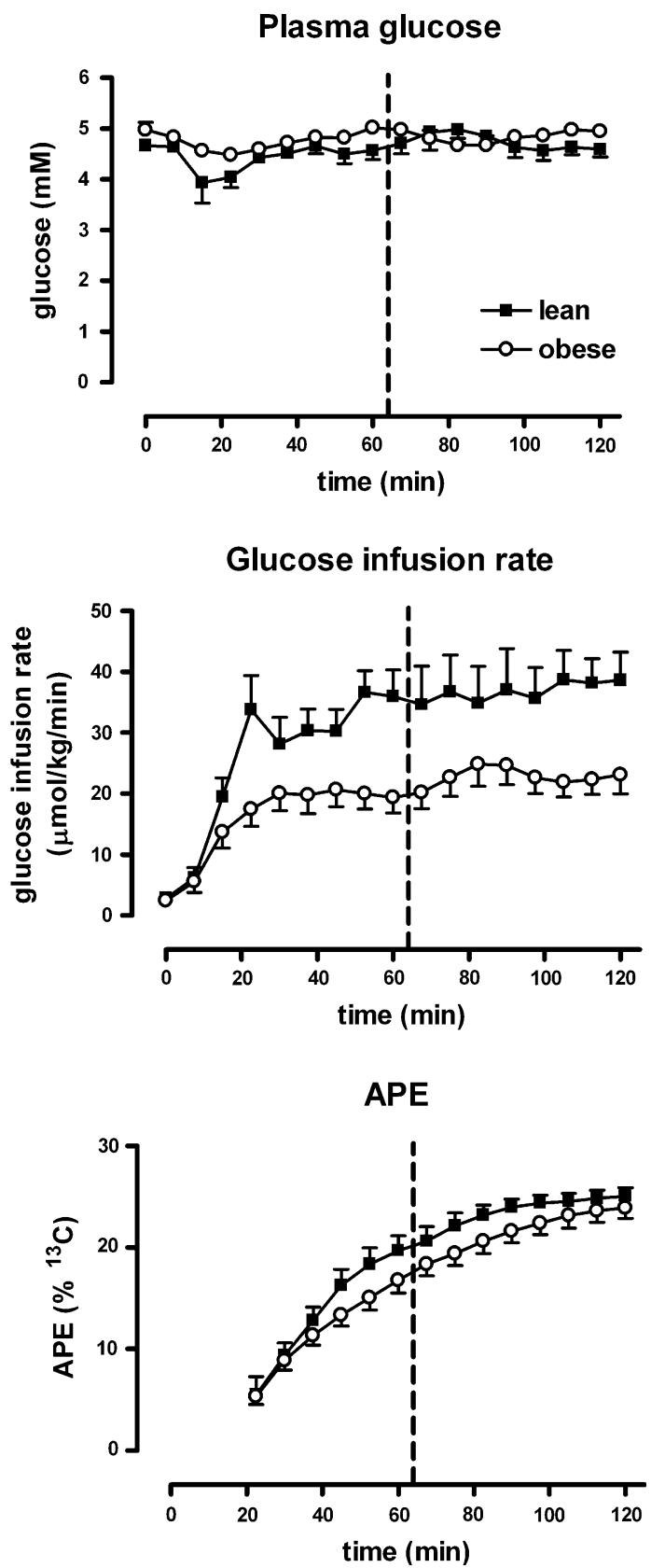

Fig. 1 Euglycemic hyperinsulinemic clamp procedure. Glucose remains constant, while insulin levels increase. Time series of plasma glucose (upper row), glucose infusion rate (middle row) and increase in APE ${ }^{13} \mathrm{C}$ glucose in blood due to $\left[1-{ }^{13} \mathrm{C}\right]$ glucose infusion (lower row). Data for lean subjects are indicated by black squares and data for obese subjects by open circles. The dashed vertical line indicates the time at which the exercise was performed

group. For both groups, insulin-stimulated glycogen synthesis rates before exercise are indicated at the left in Fig. 3. The difference in baseline glycogen synthesis rates approached significance $(P=0.07)$ with $78 \pm 14$ and $132 \pm 24 \mu \mathrm{mol} / \mathrm{kg}$ muscle/min for obese and lean subjects, respectively. For all subjects together, glycogen synthesis 

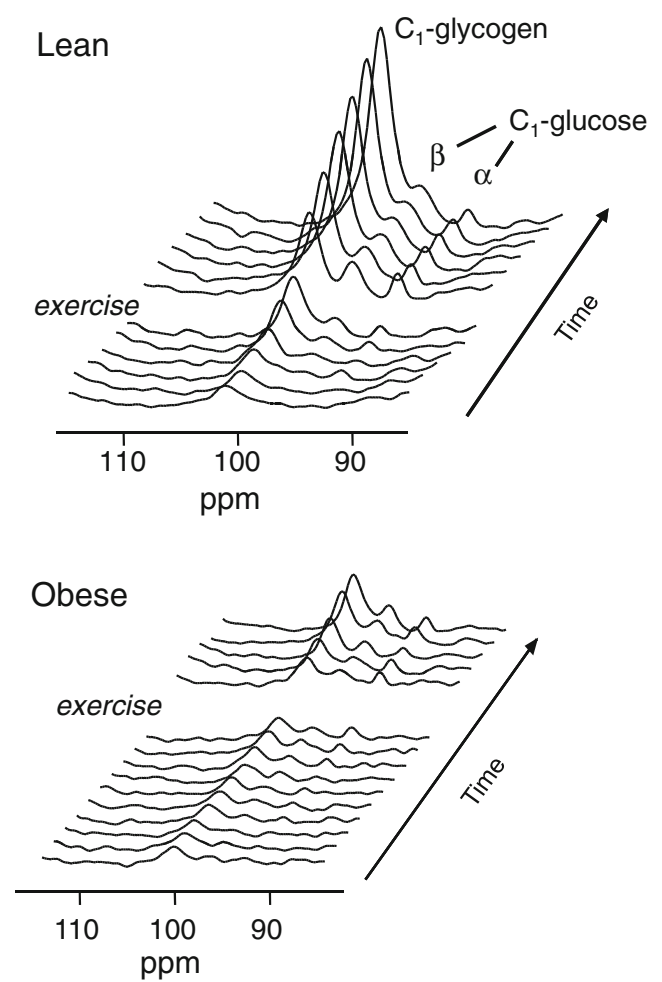

Fig. 2 Typical increase of the ${ }^{13} \mathrm{C}$ MR signals of $\left[1-{ }^{13} \mathrm{C}\right]$ glycogen and the $\alpha$ and $\beta$ anomers of $\left[1-{ }^{13} \mathrm{C}\right]$ glucose during hyperinsulinemia before and after acute exercise in (top) a lean subject and (bottom) an obese subject. Note the steeper signal increase in the spectra of the lean subject

rate during the first part of the clamp (insulin alone) strongly correlated with the whole body glucose infusion rate $(r=0.76, P=0.0002)$, as expected.

Effects of acute muscle exercise on insulin-induced glycogen synthesis

After muscle contraction (and continued insulin infusion), glycogen synthesis rate increased substantially and highly significant in both groups (see Figs. 2, 3). Still, glycogen synthesis rates after exercise were lower in the obese subjects compared with the lean subjects (obese $190 \pm 24 \mu \mathrm{mol} / \mathrm{kg}$ muscle $/ \mathrm{min}$ vs. lean $318 \pm 28 \mu \mathrm{mol} / \mathrm{kg} ; P=0.004$ ), also with a lower increment for the obese than for the lean group $(112 \pm 15$ and $186 \pm 27 \mu \mathrm{mol} / \mathrm{kg}$ muscle/min, respectively, $P=0.03)$. However, in percentages of the baseline glycogen synthesis rates, the increments did not differ between the groups $(184 \pm 35 \%$ for obese and $202 \pm 51 \%$ for lean; $P=0.78)$. The calculated workload was not significantly different amongst the different groups, although obese subjects tended to perform more work than lean subjects did (lean $3,290 \pm 184$ vs. obese $3,773 \pm 259 \mathrm{~W}, P=0.15$ ).

In Fig. 4, the exercise-induced increments in insulinstimulated glycogen synthesis rate are depicted as a function

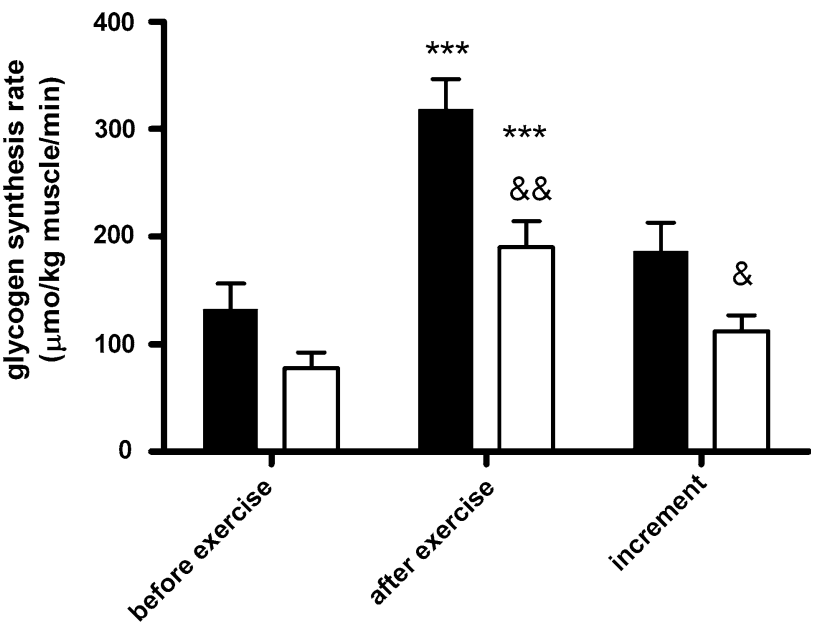

Fig. 3 Glycogen synthesis rates before and after exercise in combination with the exercise-induced increment in lean (black bars, $n=9$ ) and obese subjects (open bars, $n=9$ ). ${ }^{* * *} P=0.0001$ for lean and $P<0.0001$ for obese compared with rates before exercise; ${ }^{\& \&} P=0.004$ compared with lean; ${ }^{\&} P=0.03$ compared with lean

of whole body glucose uptake, which represents insulin sensitivity. Both individual data points (4a) and means of each group (4b) are presented. Figure $4 \mathrm{a}$ and $\mathrm{b}$ suggests a positive correlation between the exercise-induced increment in insulin-stimulated glycogen synthesis rate and whole body glucose uptake for all data of the two groups together. When all data are included, no significant correlation is present $(r=0.40, P=0.10)$, but this correlation becomes borderline significant ( $r=0.47, P=0.06$ ) upon exclusion of the two outlying data points of the subjects with the two highest values for whole body glucose uptake.

\section{Effects of exercise on skeletal muscle blood flow}

After muscle contraction, skeletal muscle blood flow increased substantially in the exercised leg from $1.6 \pm 0.2 \mathrm{~mL} /(\mathrm{dL} \mathrm{min})$ just before the exercise, to $15.6 \pm 2.6 \mathrm{~mL} /(\mathrm{dL} \mathrm{min})$ immediately after the intervention in lean controls. Blood flow subsequently decreased rapidly and returned to baseline values after approximately $30 \mathrm{~min}$. Similarly, blood flow increased from $1.6 \pm 0.3 \mathrm{~mL} /$ (dL min) just before the intervention, to maximally $12.3 \pm 1.9 \mathrm{~mL} /(\mathrm{dL} \mathrm{min})$ immediately after contraction in obese subjects.

Blood flow in forearm and control (non-exercised) leg did not change over the course of the experiment (Fig. 5). Peak blood flow was not significantly different between the two groups. As after exercise, the increased blood flow rapidly returned to baseline, while the increase in glycogen synthesis lasted until the end of the experiments, no clear temporal relationship was observed between blood flow and glycogen synthesis. Peak blood flow after exercise did 

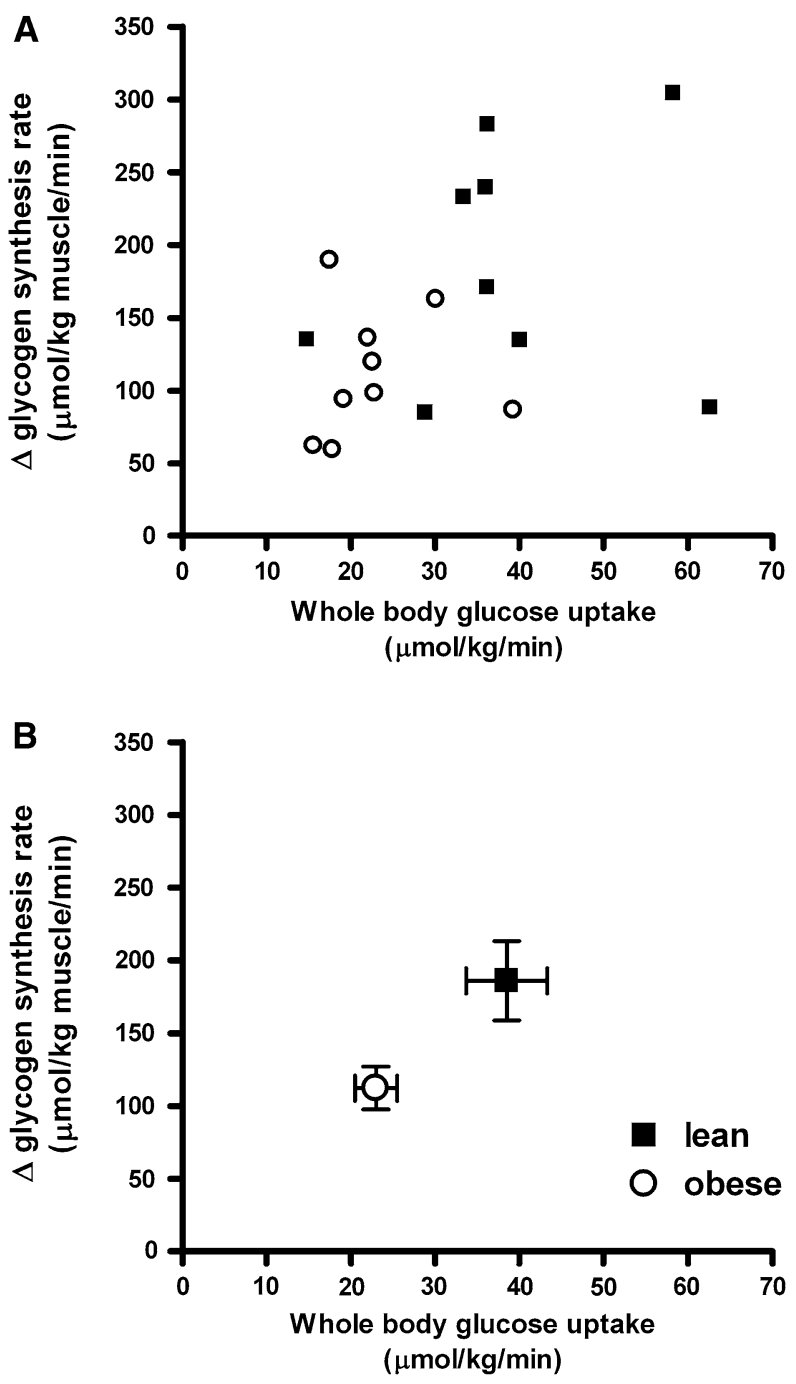

Fig. 4 Exercise-induced increments in insulin-stimulated glycogen synthesis as function of whole body glucose uptake; black squares lean, open circles obese. a Individual data and $\mathbf{b}$ mean values $( \pm$ SEM) per group

not correlate with the level of increase in insulin-induced glycogen synthesis after the intervention.

\section{Discussion}

The present study demonstrates that a short toe-lifting exercise stimulates insulin-induced glycogen synthesis in skeletal muscle and that this positive effect of acute exercise is decreased in absolute values in obese subjects, but similar in percentages of baseline glycogen synthesis rates. In addition, the short-term response to acute exercise and the level of insulin sensitivity show a tendency toward correlation. These results imply that insulin-resistant obese subjects either have defects in both the insulin-signaling pathway and the exercise-stimulated signaling pathway or
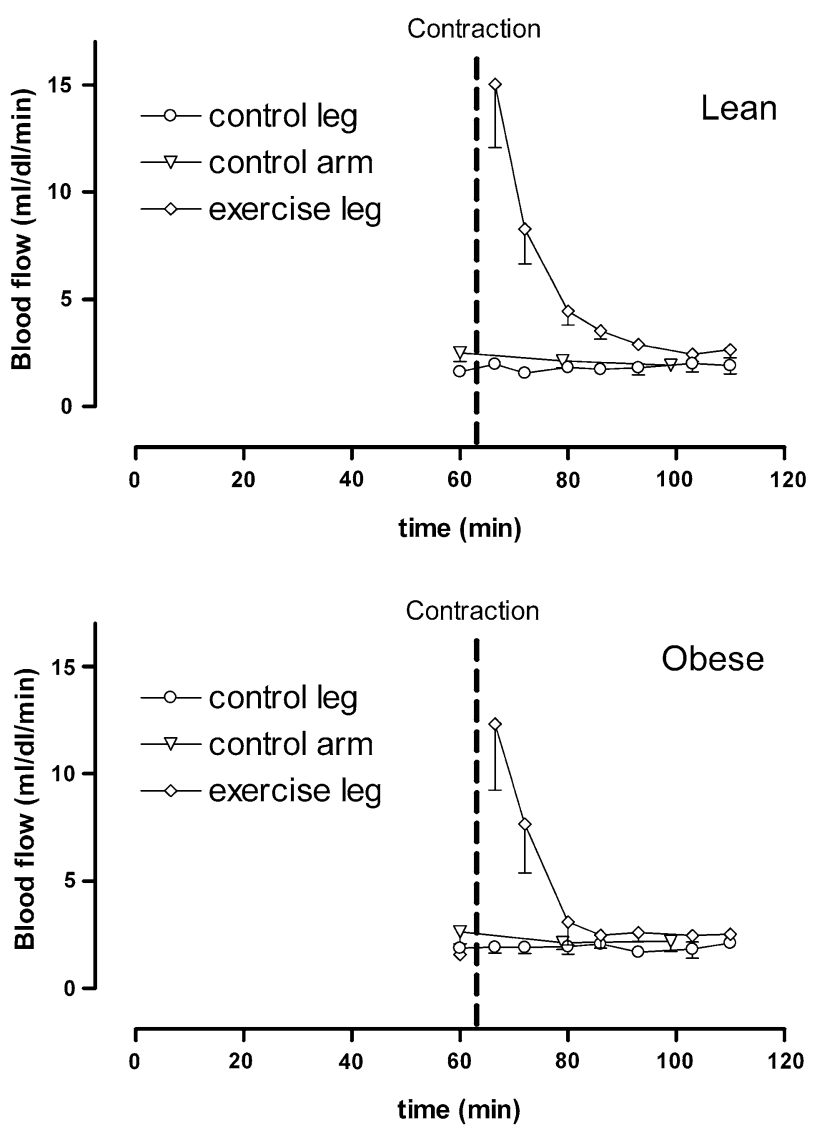

Fig. 5 Blood flow before and after exercise in lean (top, $n=5)$ and obese subjects (bottom, $n=3$ )

in a part of these pathways that the two stimuli share (see section "potential mechanism").

In our study, insulin sensitivity has been assessed by the hyperinsulinemic euglycemic clamp technique (DeFronzo et al. 1979), which induces a non-physiological state with high insulin and increased glucose disposal. Limitations of this technique are the fact that the glucose disposal rate is obtained at only a single insulin infusion rate and that the intravenously administration of insulin reverses the normal portal to peripheral insulin gradient (Muniyappa et al. 2008). The clamp technique may not accurately reflect insulin action and glucose dynamics under physiological conditions for which better a dynamic test with an oral glucose load may be used. However, the latter test has the disadvantage of continuously varying glucose and insulin levels over time, while during the clamp technique both glucose and insulin levels are stable resulting in constant flux conditions. Therefore, the clamp technique is the gold standard for direct measurement of insulin sensitivity (Kim 2009). ${ }^{13} \mathrm{C}$ MRS with ${ }^{13} \mathrm{C}$-labeled glucose infusion is a sophisticated method which allows non-invasive metabolic studies in relatively small groups of subjects. Dynamical glycogen synthesis rates can be assessed non-invasively in 
vivo without the use of radioactive materials. However, our study has some restrictions. As the dynamic ${ }^{13} \mathrm{C} \mathrm{MRS}$ method to measure glycogen synthesis requires uptake of ${ }^{13} \mathrm{C}$-labeled glucose, all measurements were carried out with insulin infusion and it was not possible to measure the effect of exercise (without insulin) on the glycogen synthesis rate separately. Further, the glycogen synthesis rate before exercise was determined during changing $\left[1-{ }^{13} \mathrm{C}\right]$ glucose APE with correction of the increment of the glycogen ${ }^{13} \mathrm{C}$ MRS signal for the APE at the specific time point. This may have resulted in a glycogen synthesis rate before exercise with lower accuracy compared with that after the intervention. Nevertheless, in another study by our group without an exercise intervention (Serlie et al. 2005) this correction resulted in a very linear concentration increase of $\left[1-{ }^{13} \mathrm{C}\right]$ glycogen in muscle between $25 \mathrm{~min}$ (with rapid changing $\mathrm{APE}$ ) and $120 \mathrm{~min}$ (with a more stable APE). Finally, the ${ }^{13} \mathrm{C}$ MRS measurements had to be performed in the early afternoon for logistic reasons. We decided to let participants use a light breakfast at least $4 \mathrm{~h}$ before the start of the experiment; both because of patient comfort, and for the reason that prolonged fasting in itself can induce insulin resistance (Hojlund et al. 2001). It was reasoned that $4 \mathrm{~h}$ should be sufficient to come to a postabsorptive state, resembling a fasting state, while at the same time prolonged fasting would be avoided. This was confirmed by the finding of fasting levels of glucose, FFA, and insulin at the start of the experiments.

None of the subjects in our study participated in any regular physical training program, and all performed the same amount of work. In fact, due to their larger weight, obese subjects tended to perform more workload, and thus the results cannot be explained by a lower exercise intensity of the obese group. Also, the lower glycogen content in the obese subjects at the start of the experiment is not likely to have influenced the results, since lower glycogen content rather may result in a higher glycogen synthesis rate after exercise (Price et al. 1994).

Blood flow appears not to influence the glycogen synthesis rate after exercise, since no correlation was found between the time course of the blood flow and the constant rate of glycogen synthesis. The response of blood flow to exercise during hyperinsulinemia does not seem to be blunted in obese subjects, suggesting that regulation of glucose uptake occurs more at the myocellular level.

Our findings seem to be in contrast to a number of animal studies, which suggest that exercise-stimulated glucose transport is not impaired in insulin-resistant conditions (Brozinick et al. 1992), if total muscle glucose transporter protein GLUT-4 is normal (Sherman et al. 1988). In addition, earlier studies in humans with type 2 diabetes also suggested that exercise-stimulated glucose transport is not impaired in insulin-resistant conditions
(Minuk et al. 1981; Martin et al. 1995). These studies applied arteriovenous differences combined with blood flow measurements and muscle biopsies to determine glycogen content. The cause of the discrepancy between the findings in diabetic subjects and those in obese individuals of the present study are not entirely clear, but a potential explanation may be a greater mass action of glucose due to the existence of hyperglycemia during the measurements in these other studies. Further, our study does not allow a separation between glucose transport and subsequent glycogen synthesis as only glycogen synthesis was measured.

However, our results are complementary to those of other studies. Peltoniemi et al. (2001) compared insulininduced glucose uptake in a resting and an exercising leg in type 1 diabetic subjects using PET. They reported that the effect of exercise on top of insulin-stimulated glucose uptake was decreased in this group of patients as compared with a control group. Similar findings were reported for obese subjects (Hällsten et al. 2003); although the reduced muscle glucose uptake in this group seems to be compensated by an increase in muscle mass. A more recent PET study suggests that exercise restores the impairment in insulin-mediated skeletal muscle perfusion and glucose delivery associated with obesity but does not normalize the defect involving the proximal steps regulating glucose disposal in obese individuals (Slimani et al. 2006). A difference between these PET studies and our study is that the PET studies showed a reduced increase of glucose uptake in obese subjects during exercise and our ${ }^{13} \mathrm{C}$ MRS measurements demonstrate a decreased stimulatory effect of exercise on glycogen synthesis directly after exercise. Perseghin et al. (1996) investigated the effect of previously performed exercise on glycogen synthesis rate using ${ }^{13} \mathrm{C}$ MRS. They reported that the percentage increase in insulin action in response to an exercise program was similar in insulin-resistant individuals with a positive family history for type 2 diabetes compared to normal controls (Perseghin et al. 1996). It should be noted that, because the baseline insulin sensitivity differed between these two groups, the insulin-resistant group showed, in fact, a diminished increase after training in absolute terms, similar as in our present study. In fact, the increments in percentages in our study also show no difference, in agreement with the results of Perseghin.

\section{Potential mechanism}

The molecular basis of a decreased insulin-stimulated glucose uptake in skeletal muscle in insulin resistance is a decreased translocation of insulin-sensitive glucose transporters (GLUT-4) to the plasma membrane (Cline et al. 1999; 
Pessin and Saltiel 2000). This translocation can also be stimulated by exercise via a route independent of insulin signaling (Lund et al. 1995). For example, phosphatidylinositol-3-kinase, which is crucial in insulin receptor signaling, is not essential for the effect of exercise on glucose uptake (O'Gorman et al. 2000). Exercise-induced translocation of GLUT-4 is suggested to be mainly regulated by $5^{\prime}$-AMP activated protein kinase, AMPK (Hayashi et al. 1998; Winder 2001; Jørgensen et al. 2006). The signaling mechanism downstream of AMPK stimulating glucose transport is still rather unclear. However, some years ago, it has been shown that the protein kinase B (Akt) substrate AS160, which is phosphorylated by Akt upon insulin stimulation, plays a key role in insulin-induced GLUT-4 translocation (Kane et al. 2002). In addition, it has been reported that in muscle cells, contraction increased AS160 phosphorylation (Bruss et al. 2005; Deshmukh et al. 2006), and in a cell-free assay, heterotrimeric AMPK complexes are able to phosphorylate AS160 (Treebak et al. 2006). Therefore, this AS160 protein may link the pathways via which exercise and insulin stimulate glucose uptake. Indeed, another rather recent study reported on attenuated exercisestimulated AMPK activity and AS160 phosphorylation in obese and type 2 diabetic subjects (Sriwijitkamol et al. 2007), which corroborates the findings of our present study. As such, there is considerable evidence for a shared molecular pathway in both insulin- and exercise-induced glucose uptake. The consequence would be that defects in the insulinsignaling pathway will result in abnormal exercise-induced metabolic action, and vice versa. Future research should delineate the exact mechanisms involved and potential strategies to overcome these defects. In such studies, a combination of stimulation of particular molecular mechanisms, e.g., stimulation of AMPK by aminoimidazole carboxamide riboside (AICAR), and detection of glucose phosphorylation or glycogen synthesis by in vivo MRS may help to gain further insight in these pathways.

\section{Conclusion}

In conclusion, our in vivo data show a stimulatory effect of a single bout of acute exercise on insulin-induced glycogen synthesis rate, which is lower in obese subjects with reduced insulin sensitivity. However, the relative exerciseinduced effect as percentage of baseline glycogen synthesis rate is similar for obese and lean subjects. These findings suggest the presence of a shared pathway between insulinand exercise-induced glucose uptake and subsequent glycogen synthesis.

Acknowledgments We thank Aarnout Jansen van Roosendaal, Jack van Asten, and Mariëlle Migchelsen for their contribution to this work. We gratefully acknowledge financial support by the Dutch Diabetes Foundation.

Open Access This article is distributed under the terms of the Creative Commons Attribution Noncommercial License which permits any noncommercial use, distribution, and reproduction in any medium, provided the original author(s) and source are credited.

\section{References}

Adriany G, Gruetter R (1997) A half-volume coil for efficient proton decoupling in humans at 4 tesla. J Magn Reson 125:178-184

Baron AD, Clark MG (1997) Role of blood flow in the regulation of muscle glucose uptake. Annu Rev Nutr 17:487-499

Brozinick JT Jr, Etgen GJ Jr, Yaspelkis BB III, Ivy JL (1992) Contraction-activated glucose uptake is normal in insulin-resistant muscle of the obese Zucker rat. J Appl Physiol 73:382-387

Bruss MD, Arias EB, Lienhard GE, Cartee GD (2005) Increased phoshorylation of Akt substrate of $160 \mathrm{kDa}$ (AS160) in rat skeletal muscle in response to insulin or contractile activity. Diabetes 54:41-50

Cline GW, Petersen KF, Krssak M, Shen J, Hundal RS, Trajanoski Z, Inzucchi S, Dresner A, Rothman DL, Shulman GI (1999) Impaired glucose transport as a cause of decreased insulinstimulated muscle glycogen synthesis in type 2 diabetes. N Engl J Med 341:240-246

Cushman SW, Goodyear LJ, Pilch PF, Ralston E, Galbo H, Ploug T, Kristiansen S, Klip A (1998) Molecular mechanisms involved in GLUT4 translocation in muscle during insulin and contraction stimulation. Adv Exp Med Biol 441:63-71

De Haan JH, Van Den Bergh AJ, Smits P, Tack CJ, Heerschap A (2002) Effects of short-duration skeletal muscle exercise and ischemia on glycogen synthesis during hyperinsulinemia. A study using ${ }^{13} \mathrm{C}$-magnetic resonance spectroscopy (Abstract). Proc Intl Soc Magn Res Med 10:169

DeFronzo RA, Tobin JD, Andres R (1979) Glucose clamp technique: a method for quantifying insulin secretion and resistance. Am J Physiol 237:E214-E223

Deshmukh A, Coffey VG, Zhong Z, Chibalin AV, Hawley JA, Zierath JR (2006) Exercise-induced phosphorylation of the novel Akt substrates AS160 an filamin A in human skeletal muscle. Diabetes 55:1776-1782

Hällsten K, Yki-Järvinen H, Peltoniemi P, Oikonen V, Takala T, Kemppainen J, Laine H, Bergman J, Bolli GB, Knuuti J, Nuutila P (2003) Insulin- and exercise-stimulated skeletal muscle blood flow and glucose uptake in obese men. Obes Res 11:257-265

Hayashi T, Hirshman MF, Kurth EJ, Winder WW, Goodyear LJ (1998) Evidence for $5^{\prime}$ AMP-activated protein kinase mediation of the effect of muscle contraction on glucose transport. Diabetes 47:1369-1373

Hojlund K, Wildner-Christensen M, Eshøj O, Skjaerbaek C, Holst JJ, Koldkjaer O, Møller Jensen D, Beck-Nielsen H (2001) Reference intervals for glucose, beta-cell polypeptides, and counterregulatory factors during prolonged fasting. Am J Physiol Endocrinol Metab 280:E50-E58

Ith M, Jung B, Zehnder M, Zwygart K, Kreis R, Boesch C (2003) Absolute quantitation of glycogen by means of ${ }^{13} \mathrm{C}$-MRS: a comparison of two different approaches (Abstract). Proc Intl Soc Magn Reson Med 11:261

Ivy JL, Kuo CH (1998) Regulation of GLUT4 protein and glycogen synthase during muscle glycogen synthesis after exercise. Acta Physiol Scand 162:295-304 
Jørgensen SB, Richter EA, Wojtaszewski JFP (2006) Role of AMPK in skeletal muscle metabolic regulation and adaptation in relation to exercise. J Physiol 574:17-31

Kane S, Sano H, Liu SC, Asara JM, Lane WS, Garner CC, Lienhard GE (2002) A method to identify serine kinase substrates: Akt phosphorylates a novel adipocyte protein with a Rab GTPaseactivating protein (GAP) domain. J Biol Chem 277:22115-22118

Kennedy JW, Hirshman MF, Gervino EV, Ocel JV, Forse RA, Hoenig SJ, Aronson D, Goodyear LJ, Horton ES (1999) Acute exercise induces GLUT4 translocation in skeletal muscle of normal human subjects and subjects with type 2 diabetes. Diabetes 48:1192-1197

Kim JK (2009) Hyperinsulinemic-euglycemic clamp to assess insulin sensitivity in vivo. Methods Mol Biol 560:221-238

Lund S, Holman GD, Schmitz O, Pedersen O (1995) Contraction stimulates translocation of glucose transporter GLUT4 in skeletal muscle through a mechanism distinct from that of insulin. Proc Natl Acad Sci USA 92:5817-5821

Martin IK, Katz A, Wahren J (1995) Splanchnic and muscle metabolism during exercise in NIDDM patients. Am J Physiol 269:E583-E590

Minuk HL, Vranic M, Marliss EB, Hanna AK, Albisser AM, Zinman B (1981) Glucoregulatory and metabolic response to exercise in obese non-insulin-dependent diabetes. Am J Physiol 240:E458-E464

Muniyappa R, Lee S, Chen H, Quon MJ (2008) Current approaches for assessing insulin sensitivity and resistance in vivo: advantages, limitations, and appropriate usage. Am J Physiol Endocrinol Metab 294:E15-E26

O'Gorman DJ, Del Aguila LF, Williamson DL, Krishnan RK, Kirwan JP (2000) Insulin and exercise differentially regulate PI3-kinase and glycogen synthase in human skeletal muscle. J Appl Physiol 89:1412-1419

Peltoniemi P, Yki-Järvinen H, Oikonen V, Oksanen A, Takala TO, Rönnemaa T, Erkinjuntti M, Knuuti MJ, Nuutila P (2001) Resistance to exercise-induced increase in glucose uptake during hyperinsulinemia in insulin-resistant skeletal muscle of patients with type 1 diabetes. Diabetes 50:1371-1377

Perseghin G, Price TB, Petersen KF, Roden M, Cline GW, Gerow K, Rothman DL, Shulman GI (1996) Increased glucose transportphosphorylation and muscle glycogen synthesis after exercise training in insulin-resistant subjects. N Engl J Med 335:1357-1362

Pessin JE, Saltiel AR (2000) Signaling pathways in insulin action: molecular targets of insulin resistance. J Clin Invest 106:165-169

Price TB, Rothman DL, Taylor R, Avison MJ, Shulman GI, Shulman RG (1994) Human muscle glycogen resynthesis after exercise: insulin-dependent and -independent phases. J Appl Physiol 76:104-111

Price TB, Perseghin G, Duleba A, Chen W, Chase J, Rothman DL, Shulman RG, Shulman GI (1996) NMR studies of muscle glycogen synthesis in insulin-resistant offspring of parents with non-insulin-dependent diabetes mellitus immediately after glycogen-depleting exercise. Proc Natl Acad Sci USA 93:5329-5334

Rattigan S, Wheatley C, Richards SM, Barrett EJ, Clark MG (2005) Exercise and insulin-mediated capillary recruitment in muscle. Exerc Sport Sci Rev 33:43-48

Richter EA, Mikines KJ, Galbo H, Kiens B (1989) Effect of exercise on insulin action in human skeletal muscle. J Appl Physiol 66:876-885
Serlie MJ, de Haan JH, Tack CJ, Verberne HJ, Ackermans MT, Heerschap A, Sauerwein HP (2005) Glycogen synthesis in human gastrocnemius muscle is not representative of whole-body muscle glycogen synthesis. Diabetes 54:1277-1282

Sherman WM, Katz A, Cutler CL, Withers RT, Ivy JL (1988) Glucose transport: locus of muscle insulin resistance in obese Zucker rats. Am J Physiol 255:E374-E382

Shulman GI, Rothman DL, Jue T, Stein P, DeFronzo RA, Shulman RG (1990) Quantitation of muscle glycogen synthesis in normal subjects and subjects with non-insulin-dependent diabetes by ${ }^{13} \mathrm{C}$ nuclear magnetic resonance spectroscopy. $\mathrm{N}$ Engl J Med 322:223-228

Slimani L, Oikonen V, Hällsten K, Savisto N, Knuuti J, Nuutila P, Iozzo P (2006) Exercise restores skeletal muscle glucose delivery but not insulin-mediated glucose transport and phosphorylation in obese subjects. J Clin Endocrinol Metab 91:3394-3403

Slotboom J, Fluck C, Kreis R, Jung B, Nuoffer JM, Boesch C (1998) Reproducibility and absolute quantification of human liver glycogen from $1 \mathrm{H}$ decoupled ${ }^{13} \mathrm{C}$ spectra using exact $\mathrm{RF}$ coil information, MRI and an external reference at 1.5T (Abstract). Proc Intl Soc Magn Reson Med 6:1860

Sriwijitkamol A, Coletta DK, Wajcberg E, Balbontin GB, Reyna SM, Barrientes J, Eagan PA, Jenkinson CP, Cersosimo E, DeFronzo RA, Sakamoto K, Musi N (2007) Effect of acute exercise on AMPK signaling in skeletal muscle of subjects with type 2 diabetes: a time-course and dose-response study. Diabetes $56: 836-848$

Tack CJ, Ong MK, Lutterman JA, Smits P (1998) Insulin-induced vasodilatation and endothelial function in obesity/insulin resistance. Effects of troglitazone. Diabetologia 41:569-576

Thorell A, Hirshman MF, Nygren J, Jorfeldt L, Wojtaszewski JF, Dufresne SD, Horton ES, Ljungqvist O, Goodyear LJ (1999) Exercise and insulin cause GLUT-4 translocation in human skeletal muscle. Am J Physiol 277:E733-E741

Treebak JT, Glund S, Deshmukh A, Klein DK, Long YC, Jensen TE, Jørgensen SB, Viollet B, Andersson L, Neumann D, Wallimann T, Richter EA, Chibalin AV, Zierath JR, Wojtaszewski JF (2006) AMPK-mediated AS160 phosphorylation in skeletal muscle is dependent on AMPK catalytic and regulatory subunits. Diabetes 55:2051-2058

Van den Bergh AJ, Tack CJ, Van den Boogert HJ, Vervoort G, Smits P, Heerschap A (2000) Assessment of human muscle glycogen synthesis and total glucose content by in vivo ${ }^{13} \mathrm{C}$ MRS. Eur $\mathbf{J}$ Clin Invest 30:122-128

Van der Graaf M, Tack CJ, de Haan JH, Klomp DW, Heerschap A (2010) Magnetic resonance spectroscopy shows an inverse correlation between intramyocellular lipid content in human calf muscle and local glycogen synthesis rate. NMR Biomed 23:133-141

Winder WW (2001) Energy-sensing and signaling by AMP-activated protein kinase in skeletal muscle. J Appl Physiol 91:1017-1028

Wojtaszewski JF, Jørgensen FB, Frøsig D, MacDonald C, Birk JB, Richter EA (2003) Insulin signalling: effects of prior exercise. Acta Physiol Scand 178:321-328 